children between composite score of asthma severity, atopic parameters and FeNO [10].

In conclusion, clinical questions of the Asthma Control Questionnaire, forced expiratory volume in one second and exhaled nitric oxide fraction were grouped in distinct components, suggesting that they may complement each other in the assessment of asthma status. Further research, particularly observational longitudinal studies, should assess the usefulness of inflammatory biomarkers in conjunction with clinical questions and lung function parameters in asthma control assessment, and eventually establish an algorithm for treatment adjustment based on a thorough measure of asthma control.

\section{Lopes ${ }^{* \#}$, J. Fonseca ${ }^{*}$, , L. Delgado*,\#, A. Moreira ${ }^{*, \#,}$ R. Barros $^{+}$, P. Moreira ${ }^{+, \S}$, M. da G. Castelo-Branco*}

*Immuno-allergology Division, Hospital of São João, "Dept of Immunology, Faculty of Medicine, "Biostatistics and Medical Informatics Division and Center for Research in Health Information Systems and Technologies (CINTESIS), Faculty of Medicine, ${ }^{+}$Faculty of Nutrition and Food Sciences, and ${ }^{\S}$ Research Centre in Physical Activity, Health and Leisure, University of Porto, Porto, Portugal.

\section{STATEMENT OF INTEREST}

None declared.

\section{ACKNOWLEDGEMENTS}

The present authors would like to thank J. Ferraz de Oliveira (Immuno-allergology, Hospital of São João, Porto, Portugal) for help in study planning.

\section{REFERENCES}

1 National Institutes of Health, National Heart Lung, and Blood Institute, Global Strategy for Asthma Management and Prevention - Global Initiative for Asthma (GINA). www.ginasthma.org Date last updated: 2007. Date last accessed: December 2007.

2 Smith AD, Cowan JO, Brassett KP, Herbison GP, Taylor DR. Use of exhaled nitric oxide measurements to guide treatment in chronic asthma. N Engl J Med 2005; 352: 2163-2173.

3 LeBlanc A, Robichaud P, Lacasse Y, Boulet LP. Quantification of asthma control: validation of the Asthma Control Scoring System. Allergy 2007; 62: 120-125.

4 Jatakanon A, Lim S, Kharitonov SA, Chung KF, Barnes PJ. Correlation between exhaled nitric oxide, sputum eosinophils, and methacholine responsiveness in patients with mild asthma. Thorax 1998; 53: 91-95.

5 Michils A, Baldassarre S, Van Muylem A. Exhaled nitric oxide and asthma control: a longitudinal study in unselected patients. Eur Respir J 2008; 31: 539-546.

6 Recommendations for standardized procedures for the online and off-line measurement of exhaled lower respiratory nitric oxide and nasal nitric oxide in adults and children -, This official statement of the American Thoracic Society was adopted by the ATS Board of Directors, July 1999. Am J Respir Crit Care Med 1999 1999; 160: 2104-2117.

7 Juniper EF, Bousquet J, Abetz L, Bateman ED. Identifying "well-controlled" and "not well-controlled" asthma using the Asthma Control Questionnaire. Respir Med 2006; 100: 616-621.

8 Rosi E, Ronchi MC, Grazzini M, Duranti R, Scano G. Sputum analysis, bronchial hyperresponsiveness, and airway function in asthma: results of a factor analysis. J Allergy Clin Immunol 1999; 103: 232-237.

9 Gronke L, Kanniess F, Holz O, Jorres RA, Magnussen H. The relationship between airway hyper-responsiveness, markers of inflammation and lung function depends on the duration of the asthmatic disease. Clin Exp Allergy 2002; 32: 57-63.

10 Leung TF, Wong GW, Ko FW, Lam CW, Fok TF. Clinical and atopic parameters and airway inflammatory markers in childhood asthma: a factor analysis. Thorax 2005; 60: 822-826.

DOI: 10.1183/09031936.00093008

\title{
Breathless after separation... from tumour
}

\section{To the Editors:}

It is a general property of the G-protein coupled receptor family, which includes adrenergic receptors, to attenuate their response after persistent stimulation [1]. However, the airway tolerance to $\beta_{2}$-agonists and the phenomenon of rebound bronhoconstriction after $\beta_{2}$-agonist withdrawal seems not to have clinical significance [2] even though it differs between compounds [3].

Herein, we report the case of a patient who developed severe bronchial obstructive symptoms after sudden interruption of a chronic stimulation of the airway catecholamine receptors by their endogenous agonists.

The patient was an 84-yr-old, nonsmoking, healthy female with no previous history of asthma or lung disorders. She attended a gym regularly, where she observed that her resting cardiac frequency increased to 110 beats $\cdot \mathrm{min}^{-1}$. During the investigation of her tachycardia, a right-sided $48 \times 52 \times 55-\mathrm{mm}$ adrenal tumour was found. Laboratory testing of the patient's urine revealed highly increased levels of noradrenaline $\left(8,780 \mathrm{nmol} \cdot \mathrm{day}^{-1}\right.$; normal value $\left.<400 \mathrm{nmol} \cdot \mathrm{day}^{-1}\right)$ and $\mathrm{mod}-$

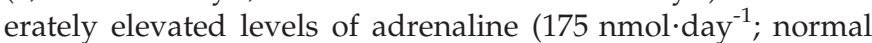
value $<80 \mathrm{nmol} \cdot \mathrm{day}^{-1}$ ) confirming the diagnosis of pheochromocytoma. The patient was prepared carefully for surgery by stepwise increase of the $\alpha$-blocker doxazosin to a dose of $32 \mathrm{mg}$ daily at the time of surgery and diltiazem (180 mg daily), which was preferred to $\beta$-blockers for treating her tachyarrhythmia. After successful laparoscopic removal of the tumour, the patient developed severe bronchospasm and had to be treated with glucocorticoids and inhaled $\beta_{2}$-agonists. The obstructive symptoms lasted $<1$ week. 
Bronchoconstriction, after removal of a catecholamine-producing tumour, is physiologically foreseeable owing to the sudden deprivation of catecholamines, as well as deprivation of other tumour-secreted bronchodilator substances, such as adrenomedullin [4], vasoactive intestinal peptide or pituitary adenylate cyclase-activating peptide [5]. There are, however, few reports of respiratory problems in patients with pheochromocytoma and all, in contrast to ours, had a history of asthma and/or were being treated with $\beta$-blockers $[6,7]$. Our patient has, since the acute post-operative period, been feeling perfectly well. She is back in the gym on a regular basis, her cardiac frequency is normal and she has not had any further respiratory problems.

It is therefore good to keep in mind that bronchospasm, and not only cardiovascular collapse, is a possible incident that can occur after removal of a catecholamine-producing tumour.

\section{S-B. Catrina and L. Juntti-Berggren}

Dept of Molecular Medicine and Surgery, Endocrine Unit, Karolinska Institutet, Karolinska Hospital, Stockholm, Sweden.

\section{REFERENCES}

1 Lefkowitz RJ, Williams LT. Molecular mechanisms of activation and desensitization of adenylate cyclase coupled $\beta$ adrenergic receptors. Adv Cyclic Nucleotide Res 1978; 9: 1-17.

2 Campbell M, Eliraz A, Johansson G, et al. Formoterol for maintenance and as-needed treatment of chronic obstructive pulmonary disease. Respir Med 2005; 99: 1511-1520.

3 Vathenen AS, Knox AJ, Higgins BG, Britton JR, Tattersfield AE. Rebound increase in bronchial responsiveness after treatment with inhaled terbutaline. Lancet 1988; 1: 554-558.

4 Kanazawa H, Kurihara N, Hirata K, Kudoh S, Kawaguchi T, Takeda T. Adrenomedullin, a newly discovered hypotensive peptide, is a potent bronchodilator. Biochem Biophys Res Commun 1994; 205: 251-254.

5 Linden A, Cardell LO, Yoshihara S, Nadel JA. Bronchodilation by pituitary adenylate cyclase-activating peptide and related peptides. Eur Respir J 1999; 14: 443-451.

6 Harvey JN, Dean HG, Lee MR. Recurrence of asthma following removal of a noradrenaline-secreting phaeochromocytoma. Postgrad Med J 1984; 60: 364-365.

7 Sastre J, Azofra J, Sastre A. Pheochromocytoma and asthma. Chest 1985; 88: 482.

\section{Statistical analysis of COPD exacerbations}

\section{From the authors:}

We would like to thank S. Suissa for his letter, which appeared in a recent issue of the European Respiratory Journal [1]. We share his interest in the methodology of chronic obstructive pulmonary disease (COPD) trials. The issues he raised are important and deserve a more comprehensive response than is possible here. We would, however, like to address the two major points regarding the design of the TRISTAN (Trial of Inhaled Steroids and Long-acting $\beta_{2}$-agonists) and ISOLDE (Inhaled Steroids in Obstructive Lund Disease) trials, which lead him to claim that the trials "violate fundamental principles of randomised trial methodology" [1].

First, S. Suissa contends that intent-to-treat analysis is impossible when there is incomplete follow-up of patients who withdraw from the study [1]; but this assertion is incorrect. Intent-to-treat analysis does require inclusion of all available subjects in the analysis but the principle allows for missing data. The CONSORT (Consolidated Standards of Reporting Trials) statement is the standard guideline for reporting randomised clinical trials adopted by major medical journals [2]. An accompanying article to the 2001 revision of CONSORT states: "It is common for some patients not to complete a study - they may drop out or be withdrawn from active treatment - and thus are not assessed at the end. Although these patients cannot be included in the analysis, it is customary still to refer to analysis of all available participants as an intent-to-treat analysis" [3]. In the analysis of TRISTAN and ISOLDE, all available patients were included and therefore the results presented are from a valid intent-to-treat analysis.

Secondly, S. Suissa states that the design of COPD trials needs to be stratified by prior use of inhaled corticosteroids (ICS) and suggests that this deficiency "cannot simply be corrected by data analysis" [1]. Stratifying a design by important predictors of outcome can be helpful in terms of ensuring balance, but it is not essential for data analysis. In large trials, randomisation will lead to similar proportions of patients in each treatment arm with prior use of ICS. Indeed, the standard textbook on clinical trials, Clinical Trials: a Practical Approach, states: "if the trial is very large, say several hundred patients [...] then stratification has little point" [4]

Thus, the designs of ISOLDE and TRISTAN conform to conventional clinical trial methodology and therefore have no major flaws. It remains valid to draw conclusions regarding the effectiveness of inhaled corticosteroids based on their outcome.

O.N. Keene*, P.M.A. Calverley ${ }^{\#}$, P.W. Jones ${ }^{\top}$, J. Vestbo $^{+}$and J.A. Anderson*

*GlaxoSmithKline, Uxbridge, "Dept of Medicine, Clinical Sciences Centre, The University Hospital Aintree, Liverpool, 